\title{
AVALIAÇÃO DA ARBORIZAÇÃO DE RUAS DO BAIRRO SÃO DIMAS NA CIDADE DE PIRACICABA/SP ATRAVÉS DE PARÂMETROS QUALITATIVOS
}

\author{
Andrea Volpe-Filik ${ }^{1}$, Luzia Ferreira da Silva ${ }^{2}$, Ana Maria Liner Pereira Lima ${ }^{3}$
}

\section{RESUMO}

Os problemas relacionados com a falta de manejo da arborização urbana já podem ser percebidos nas cidades, e, com o intuito de verificar a situação atual das árvores viárias, este trabalho buscou levantar parâmetros, tais como poda, injúrias no tronco, área livre do canteiro e afloramento de raízes na calçada da arborização do bairro São Dimas, Piracicaba/SP. Os dados foram coletados em uma planilha de campo, observando os itens: nome comum da espécie, tipo de poda, análise do tronco, do sistema radicular e do canteiro. Nos dados coletados foram analisados 253 indivíduos com total de 38 espécies, sendo $50 \%$ de arbustos, $44 \%$ de árvores e 5,5\% de palmeiras. Nos indivíduos observados, $69 \%$ das podas efetuadas foram classificadas como ruins e $46 \%$ pode ser classificada como pesada. Em relação a injúrias encontradas no tronco das espécies, observa-se que $86 \%$ das árvores estão sem lesões, não considerando as podas pesadas e ruins. Em relação ao sistema radicular dos indivíduos amostrados, 63\% não estavam com raízes aparentes. Verificou-se que $56 \%$ dos canteiros analisados estavam suficientes para o momento presente, sendo que, no futuro, estes deverão ser ampliados, $44 \%$ foram classificados como insuficientes, e $8 \%$ dos canteiros completamente pavimentados.

Palavras-chave: arborização urbana, poda, afloramento de raiz, área livre do canteiro.

\footnotetext{
${ }^{1}$ Engenheira Agrônoma, doutoranda da Universidade de São Paulo junto a Escola Superior de Agricultura "Luiz de Queiroz", Departamento de Produção Vegetal, avfilik@esalq.usp.br

${ }^{2}$ Engenheira Agrônoma, doutoranda da Universidade de São Paulo junto a Escola Superior de Agricultura "Luiz de Queiroz", Departamento de Produção Vegetal, Ifsilva@esalq.usp.br

${ }^{3}$ Engenheira Agrônoma, professora titular da Universidade de São Paulo junto a Escola Superior de Agricultura

"Luiz de Queiroz", Departamento de Produção Vegetal, amlplima@esalq.usp.br
} 


\title{
EVALUATION OF STREETS ARBORIZATION OF THE QUARTER SÂO DIMAS AT THE CITY OF PIRACICABA/SP THROUGH QUALITATIVE PARAMETERS
}

\begin{abstract}
The problems related with the lack of management of the urban arborization already can be perceived in the cities, and, with intention to verify the current situation of the street trees, this work searched to raise parameters, such as it pruning, injuries in the trunk, free area of the seedbed and outcrop of root in the sidewalk of the arborization of the quarter São Dimas, Piracicaba/SP. The data had been collected in a field spread sheet, observing: common name of the species, type of pruning, analysis of the trunk, the radicular system and the seed-bed. In the collected data 253 individuals with total of 38 species, being $50 \%$ of shrubs, $44 \%$ of trees and $5.5 \%$ of palms had been analyzed. In the observed individuals, $69 \%$ of the effected prunings had been classified as bad and $46 \%$ can be classified as heavy. In relation the injuries found in the trunk of the species, are observed that $86 \%$ of the trees are without injuries, not considering the heavy and bad prunings. In relation to the radicular system of the showed individuals, $63 \%$ were not with apparent roots. It was verified that $56 \%$ of the analyzed seed-beds were enough for the present moment, being that, in the future, these will have to be extended, $44 \%$ had been classified as insufficient, and $8 \%$ of the seed-beds completely paved.
\end{abstract}

Key words: urban arborization, pruning, outcrop of root, free area of the seed-bed. 


\section{INTRODUÇÃO}

As árvores desempenham um papel vital para o bem-estar das comunidades urbanas; sua capacidade única em controlar muitos dos efeitos adversos do meio urbano, deve contribuir para uma significativa melhoria da qualidade de vida, exigindo uma crescente necessidade por áreas verdes urbanas a serem manejadas como um recurso de múltiplo uso em prol de toda a comunidade.

Segundo MELLO FILHO (1985), as principais funções da arborização urbana são: função química - absorção do gás carbônico e liberação do oxigênio, melhorando a qualidade do ar urbano; função fisica - oferta de sombra, absorção de ruídos e proteção térmica; função paisagística - quebra da monotonia da paisagem, pelos diferentes aspectos e texturas; função ecológica - abrigo e alimento aos animais e função psicológica - bem estar às pessoas proporcionado pelas massas verdes.

Mesmo condicionando tantos benefícios, de acordo com LIMA (1993), as árvores de ruas e avenidas, no geral, continuam sendo danificadas, mutiladas ou aérea mesmo eliminadas quando se trata de alargamento de ruas, conserto de encanamentos, manutenção de fiação, construção ou reforma de casas, entre outros.

Se, já apresentam-se grandes as dificuldades de se implantar o verde nas cidades, principalmente, conciliado à presença de equipamentos urbanos como instalações hidráulicas, redes elétricas, telefônicas ou sanitárias (SOARES, 1998), muito mais problemático, ainda, é tratar de sua manutenção.

No ambiente urbano, a relação árvore e poda está tão arraigada na mente das pessoas que estas acreditam realizar a melhor prática. No entanto, a poda de árvores é uma agressão, pois elas possuem uma forma estrutural bem definida e poucos mecanismos de defesa. Na execução de podas, principalmente, a poda de manutenção, deve ser dada especial atenção à morfologia da base do galho, pois na inserção do galho no tronco principal, distinguem-se duas estruturas: a crista na parte superior e o colar na parte inferior da base do galho, que são de vital importância para garantir a cicatrização do lenho (compartimentalização do lenho) (SEITZ, 1990).

Em função do exposto, este trabalho buscou levantar parâmetros, de vital importância em proporcionar uma arborização de qualidade, tais como poda, injúrias no tronco, área livre do canteiro e afloramento de raízes na calçada da arborização viária do bairro São Dimas, Piracicaba/SP, com o intuito de verificar o manejo da arborização e sua situação atual. 


\section{MATERIAIS E MÉTODOS}

A cidade de Piracicaba situa-se entre as coordenadas geográficas $22^{\circ} 42^{\prime} 31^{\prime \prime}$ de latitude sul e 47038'01" de latitude oeste Greenwich. O clima da região é classificado como subtropical úmido, com verão chuvoso (excedente hídrico $=254 \mathrm{~mm}$ ) e inverno seco (deficiência hídrica $=70 \mathrm{~mm}$ ). A temperatura média anual é de $21,6^{\circ} \mathrm{C}$.

Para levantamento dos dados no bairro São Dimas, a amostragem foi totalmente ao acaso, com sorteio de 10 quadras do total de 67.

Os dados foram coletados no mês de junho de 2005, em uma planilha de campo, observando os itens:

a) Nome comum da espécie;

b) Tipo de poda:

1. sem poda

2. de condução

3. topiaria

4. forma em $\mathrm{V}$

5. forma de L

6. drástica ou mutilada

7. poda leve (diâmetro $<5 \mathrm{~cm}$ ) a. boa (preservou crista e colar)

b. ruim (não preservou crista e colar, deixou toco)

8. pesada (diâmetro $>5 \mathrm{~cm}$ ) a. boa

b.ruim

c) Tronco:

1. sem injúrias

2. oco, com cavidades

3. longitudinais

4. anelamento completo

5. inclinado

6. com injúrias

d) Sistema radicular:

1. não aparente

2. aparente

3. afetando calçada

4. afetando guia

5. afetando muro

e) Canteiro: 
1. colo pavimentado

2. suficiente (com mais de $10 \mathrm{~cm}$ de terra ao redor do tronco)

3. insuficiente (com menos de $10 \mathrm{~cm}$ de terra ao redor do tronco)

\section{RESULTADOS E DISCUSSÃO}

Nos dados coletados foram analisados 253 indivíduos com total de 38 espécies, sendo 50\% de arbustos, $44 \%$ de árvores e 5,5\% de palmeiras. Nos indivíduos observados, $69 \%$ das podas efetuadas ( $24 \%$ leve ruim, $41 \%$ pesada ruim e $4 \%$ leve e pesada ruim) foram classificadas como ruins (Tabela 1), evidenciando um manejo inadequado por parte da prefeitura ou pela população. Embora exista uma lei municipal que proíbe o munícipe de efetuar podas na árvore, estas ocorrem com freqüência e de maneira inadequada, em função da grande demanda de solicitações ao órgão público municipal.

Das podas analisadas, 46\% (1\% pesada boa, $41 \%$ pesada ruim e $4 \%$ leve e pesada ruim) pode ser classificada como pesada, demonstrando, mais uma vez, que o manejo inadequado da arborização da arborização, ao verificá-las sendo efetuadas em galhos com diâmetro maior que $5 \mathrm{~cm}$; caso houvesse um manejo adequado, estas podas teriam sido efetuadas anteriormente, no momento oportuno, sem causar danos maiores ao exemplar arbóreo, agora adulto.

As lesões causadas por poda devem ser reduzidas ao máximo, pois funcionarão como entradas potenciais para microrganismos apodrecedores, insetos ou doenças, além de exigirem um tratamento extensivo e oneroso, muitas vezes infrutífero, em árvores isoladas, espalhadas pela cidade (MILANO \& DALCIN, 2000). Ainda, a poda ocasiona um desequilíbrio na planta (folha-raiz) provocando uma reação de compensação na árvore proporcionalmente à sua intensidade, desencadeando a quebra da dormência das gemas epicórmicas (brotos ladrões), levando a uma rápida brotação e descaracterizando o modelo arquitetônico original da espécie. De grande importância, acaba sendo, além do comprometimento fitotécnico, também os gastos onerosos com tal atividade. 
Tabela 1. Podas efetuadas nas espécies encontradas nas vias amostradas do bairro São Dimas,Piracicaba/SP: poda leve (diâmetro $<5 \mathrm{~cm}$ ), poda pesada (diâmetro $>5 \mathrm{~cm}$ ), boa (preservou crista e colar), ruim (não preservou crista e colar, deixou toco).

\begin{tabular}{|l|c|c|}
\hline Tipo de Poda & Quantidade & Porcentagem (\%) \\
\hline Leve boa & 15 & 6 \\
\hline Leve ruim & 60 & 24 \\
\hline Pesada boa & 2 & 1 \\
\hline Pesada ruim & 104 & 41 \\
\hline Leve e Pesada ruim & 10 & 4 \\
\hline Sem poda & 62 & 24 \\
\hline Total & 253 & 100 \\
\hline
\end{tabular}

Ainda observou-se que $5 \%$ dos exemplares sofreram poda drástica e, destes, $54 \%$ foi motivado por fiação elétrica e 46\%, sem causa aparente (Tabela 2); ficou aparente que, a idéia de que a poda se faz necessária à árvore, no sentido de embelezá-la e melhorar seu vigor, ainda existe.

A poda drástica é antieconômica, uma vez que, depois de sua execução, ocorre uma super brotação, nas proximidades do corte, de ramos que tendem a uma posição ascendente (BALENSIEFER,1987). O motivo das podas, muitas vezes, é por sua interferência nas redes elétricas, não levando em conta a morfologia da árvore, mutilando-a para favorecer tal fiação (MILANO et al.,1992). VELASCO (2003), através de um estudo com árvores estabelecidas em vias públicas e tipos de fiação, provou ser possível viabilizar uma melhor relação entre a árvore e a rede compacta, do que entre esta e a rede convencional, favorecendo o desempenho de todos os seus benefícios.

Os conflitos entre árvores e redes elétricas aéreas são vistos de maneira crítica, pois há coincidência da altura das árvores médias e grandes com as redes elétricas aéreas, gerando o mito de não planta-las sob fiação. Segundo alguns autores ( MILANO \& DALCIN ,2000), árvores de grande porte podem ser utilizadas sob redes, com restritos problemas e baixas demandas de podas. 
Tabela 2. Espécies com poda drástica encontradas nas vias amostradas do bairro São Dimas, Piracicaba/SP.

\begin{tabular}{|c|c|c|}
\hline Drástica & Quantidade & Porcentagem (\%) \\
\hline Sibipiruna & 4 & \\
\hline Resedá & 4 & \\
\hline Pitanga & 1 & \\
\hline Oiti & 1 & \\
\hline Ficus & 1 & \\
\hline Falsa murta & 1 & \\
\hline Chapéu de sol & 1 & \\
\hline Total & 13 & 5 \\
\hline Com fiação & 7 & 54 \\
\hline Sem fiação & 6 & 46 \\
\hline
\end{tabular}

Em relação a injúrias encontradas no tronco das espécies, observa-se que $86 \%$ das árvores estão sem lesões, não considerando as podas pesadas e ruins (Tabela 3). As árvores viárias estão sujeitas a grandes lesões ocasionadas por poda inadequada de galhos grossos, acidentes causados por automóveis e caminhões ou vandalismo da população, que provocam severas injúrias no tronco das árvores MILANO \& DALCIN (2000).

Tabela 3. Injúrias no tronco das espécies encontradas nas vias amostradas do bairro São Dimas, Piracicaba/SP.

\begin{tabular}{|l|c|c|}
\hline Tronco & Quantidade & Porcentagem (\%) \\
\hline Sem injúria & 217 & 86 \\
\hline Com injúria & 28 & 11 \\
\hline Oco & 3 & 1 \\
\hline Longitudinal & 4 & 2 \\
\hline Inclinado & 1 & 0 \\
\hline $\begin{array}{l}\text { Anelamento } \\
\text { completo }\end{array}$ & 1 & 0 \\
\hline Total & 253 & 100 \\
\hline
\end{tabular}

Em relação ao sistema radicular dos indivíduos amostrados, 63\% não estavam com raízes aparentes e, dos 37\% com raízes aparentes, 36\% estavam afetando a calçada (Tabela 4). 
Os danos causados pelas raízes das árvores em calçadas, sarjetas e esgotos são, em média, 25\% do custo de manutenção anual com árvores urbanas e, pelas cifras que atingem, esses problemas multimilionários precisam ser melhor estudados (MCPHERSON \& PEPER, 1996).

Tabela 4. Sistema radicular das espécies encontradas nas vias amostradas do bairro São Dimas, Piracicaba/SP.

\begin{tabular}{|l|c|c|}
\hline Sistema Radicular & Quantidade & Porcentagem (\%) \\
\hline Não aparente & 158 & 63 \\
\hline Aparente - afetando calçada & 73 & 29 \\
\hline Aparente - afetando calçada e guia & 18 & 7 \\
\hline Aparente & 4 & 1 \\
\hline Total & 253 & 100 \\
\hline
\end{tabular}

Na Tabela 5 observa-se que todas as sibipirunas (100\%) e 49\% dos oitis estão com afloramento de raízes nas calçadas.

Tabela 5. Espécies com sistema radicular afetando calçada nas vias amostradas do bairro São Dimas, Piracicaba/SP.

\begin{tabular}{|l|c|c|c|}
\hline Espécies & Total de Indivíduos & Quantidade & Porcentagem (\%) \\
\hline Sibipiruna & 26 & 26 & 100 \\
\hline Oiti & 41 & 20 & 49 \\
\hline Falsa murta & 60 & 8 & 13 \\
\hline Resedá & 19 & 6 & 32 \\
\hline
\end{tabular}

Verificou-se que $56 \%$ dos canteiros analisados estavam suficientes para o momento presente, sendo que, no futuro, estes deverão ser ampliados, e $44 \%$ foram classificados como insuficientes, demonstrando que os canteiros são vistos como dispensáveis, não só pela população como, também, pelos órgãos públicos. Foram encontrados $8 \%$ dos canteiros completamente pavimentados e, em alguns casos, o colo da planta já havia crescido por cima do cimento.

Estudos já foram feitos sobre a correlação inversa entre o tamanho da área livre de pavimentação deixada na base das árvores e danos às calçadas (MILANO, 1996). A distância que é deixada em volta do tronco é bem reduzida e as árvores com raízes mais superficiais sofrem com esta limitação. 
Tabela 6. Condições do canteiro das espécies encontradas nas vias amostradas do bairro São Dimas, Piracicaba/SP.

\begin{tabular}{|l|c|c|}
\hline Canteiro & Quantidade & Porcentagem (\%) \\
\hline Suficiente & 142 & 56 \\
\hline Insuficiente & 111 & 44 \\
\hline Total & 253 & 100 \\
\hline
\end{tabular}

\section{CONCLUSÕES}

Existe um manejo inadequado, principalmente em relação a podas mal feitas, onde deixam-se tocos e lascas no tronco, facilitando a entrada de patógenos e insetos, e um número significante de podas em galhos grossos, evidenciando o mal trato em relação a árvore; sobre as podas drásticas, quase metade delas foi efetuada sem uma causa aparente. Quanto às injúrias ocasionadas no tronco, foram observadas em pequena porcentagem, não levando em consideração o alto índice de podas mal executadas.

É necessário ampliar-se os canteiros para uma melhor interação entre planta e ambiente, diminuindo problemas com calçadas. Deve-se organizar um manejo adequado das espécies, principalmente das arbustivas (no viveiro e no local), pela prefeitura.

A população deve ser orientada, através de educação ambiental, sobre podas mal executadas e os danos causados nos exemplares, os benefícios da arborização urbana e a introdução de calçada verde como melhoria do ambiente urbano, tanto para a árvore como para a população.

\section{REFERÊNCIAS BIBLIOGRÁFICAS}

BALIENSIEFER, M. Poda em arborização urbana. Curitiba: ITCF, 1987. 27 p.

LIMA, A.M.L.P. Piracicaba, SP: analise da arborização viária na área central e seu entorno. Piracicaba, 1993. 283p. Tese (Doutorado) - Escola Superior de Agricultura "Luiz de Queiroz", Universidade de São Paulo.

MCPHERSON, E.G. \& PEPER P.P. Costs of street tree damage to infrastructure. Arboricultural Journal, v.2O, p.143-160, 1996.

MELLO FILHO, L.E. Arborização urbana. In: ENCONTRO NACIONAL SOBRE ARBORIZAÇÃo URBANA, 1, Porto Alegre, 1985. Anais. Porto Alegre. p.117-127. 1985. 
MILANO, M.S. \& DALCIN, E.C. Arborização de vias públicas. Rio de Janeiro. Light, 2000. $226 p$.

MILANO, M.S. A cidade, os espaços abertos e vegetação.In: In: ENCONTRO NACIONAL SOBRE ARBORIZAÇÃO, 4., Vitória, 1992. Anais... Vitória, Prefeitura Municipal de Vitória, 1992. p. 317-326.

SEITZ, R.A. Considerações sobre a poda de árvores na arborização urbana. In: ENCONTRO NACIONAL SOBRE ARBORIZAÇÃO URBANA, 3, Curitiba-PR, 1990. Anais.Fupef. p.87-100. 1990.

SOARES, M.P. Verdes urbanos e rurais: orientação para arborização de cidades e sítios campesinos. Porto Alegre: Cinco Continentes, 1998. 242p.

VELASCO, G. D. N. Arborização viária X sistema de distribuição de energia elétrica: avaliação dos custos, estudo das podas e levantamento de problemas fitotécnicos. Piracicaba, 2003. 94p. (Mestrado - ESALQ/USP). 